\title{
An Analysis of COVID-19 Mortality at the Local Authority Level in England
}

\author{
Noah Carl ${ }^{1}$ \\ 14 June 2020
}

${ }^{1}$ Independent researcher, UK: noah carl3742@hotmail.com 


\begin{abstract}
This study analyses COVID-19 mortality at the local authority level in England. The dependent variable is the age-standardised COVID-19 mortality rate. Two separate analyses are reported: one using untransformed variables, and one using logged variables (where appropriate). In the former, five variables explain $73 \%$ of the variance in COVID-19 mortality rate: cumulative confirmed cases rate, population density, \% black or Asian, average household size, and deprivation index. In the latter, four variables explain $72 \%$ of the variance in log COVID-19 mortality rate: log cumulative confirmed cases rate, $\log \%$ black or Asian, average household size, and deprivation index. (A health index does not reach statistical significance in either analysis, most likely because it is somewhat crude and the dependent variable is agestandardised.) Cumulative confirmed cases rate, average household size and \% black or Asian are the strongest and most consistent predictors of COVID-19 mortality.
\end{abstract}

Keywords: COVID-19, SARS-CoV-2, coronavirus, mortality, race, ethnicity 


\section{Introduction}

On 12 June 2020, the UK's Office for National Statistics published estimates of the age-standardised mortality rate for COVID-19 at the local authority level in England and Wales (ONS, 2020a; and see ONS, 2020b). These estimates correspond to deaths that occurred between 1 March and 31 May. For the purpose of analysis, they were linked with data from other sources. Identifying the area-level predictors of COVID19 mortality is important for understanding the epidemiology of the disease. Note that Rose et al. (2020) have already performed an area-level analysis of COVID-19 mortality, based on estimates they derived using data from NHS trusts. They ran negative binomial regression models, and found that \% BAME (black, Asian and minority ethnic) and \% deprivation were robust predictors of COVID-19 mortality. Population density did not reach statistical significance in their models. However, it can be instructive for different researchers to analyse the same phenomenon, since they may make different methodological choices, and may therefore reach different overall conclusions. The purpose of the present study was to examine predictors of COVID-19 at the local authority level in England.

\section{Analysis}

\subsection{Data and measures}

Estimates of the age-standardised mortality rate for COVID-19 were linked to data on the cumulative confirmed cases rate from the UK government's coronavirus dashboard (UK Government, 2020). These estimates are updated daily, but are only available for England. Values on 21 April were taken for analysis. ${ }^{2}$ The estimates of COVID-19 mortality were also linked to data from the 2011 UK census and the Office for National Statistics (ONS, 2012; ONS, 2018). Specifically, the following variables were obtained: population density; \% black or Asian; average household size; \% in multi-generational households; \% unemployed; \% with no qualifications; \% in routine occupations; \% single parent households; gross disposable household income per capita; \% reporting bad health; and \% with an activity-limiting disability. (Note that, in this context, 'Asian' refers to Britons of Indian, Bangladeshi or Pakistani origin.) After merging the data, all local authorities with a missing value on any variable were deleted. The final dataset contained 292 observations, which represents $90 \%$ of the local authorities in England.

The two measures of health (\% with bad health, and \% with a disability) were combined into a crude index of health using principal components analysis. (The first principal component explained 94\% of the variance.) Likewise, the five measures of deprivation (\% unemployed, $\%$ with no qualifications, $\%$ in routine occupations, \% single parent households, and gross disposable household income per capita) were combined into an index of socio-economic deprivation using principal components analysis. (The first principal component explained $68 \%$ of the variance.) Note that four extreme values of gross disposable household income per capita were winsorized prior to analysis.

\footnotetext{
2 These data are not available for other parts of the United Kingdom. Extracting more recent values led to an unacceptable loss of observations when merging data. Note that the daily number of confirmed cases peaked on 7 April.
} 
At the local authority level, COVID-19 mortality has a mean of 81 (per 100,000) and a standard deviation of 36. A map showing the distribution of COVID-19 mortality across local authorities in England is given in Figure 1. The most obvious pattern is that mortality is higher in urban areas, particularly in the capital city of London.

Figure 1. Map showing the distribution of COVID-19 mortality across local authorities in England.

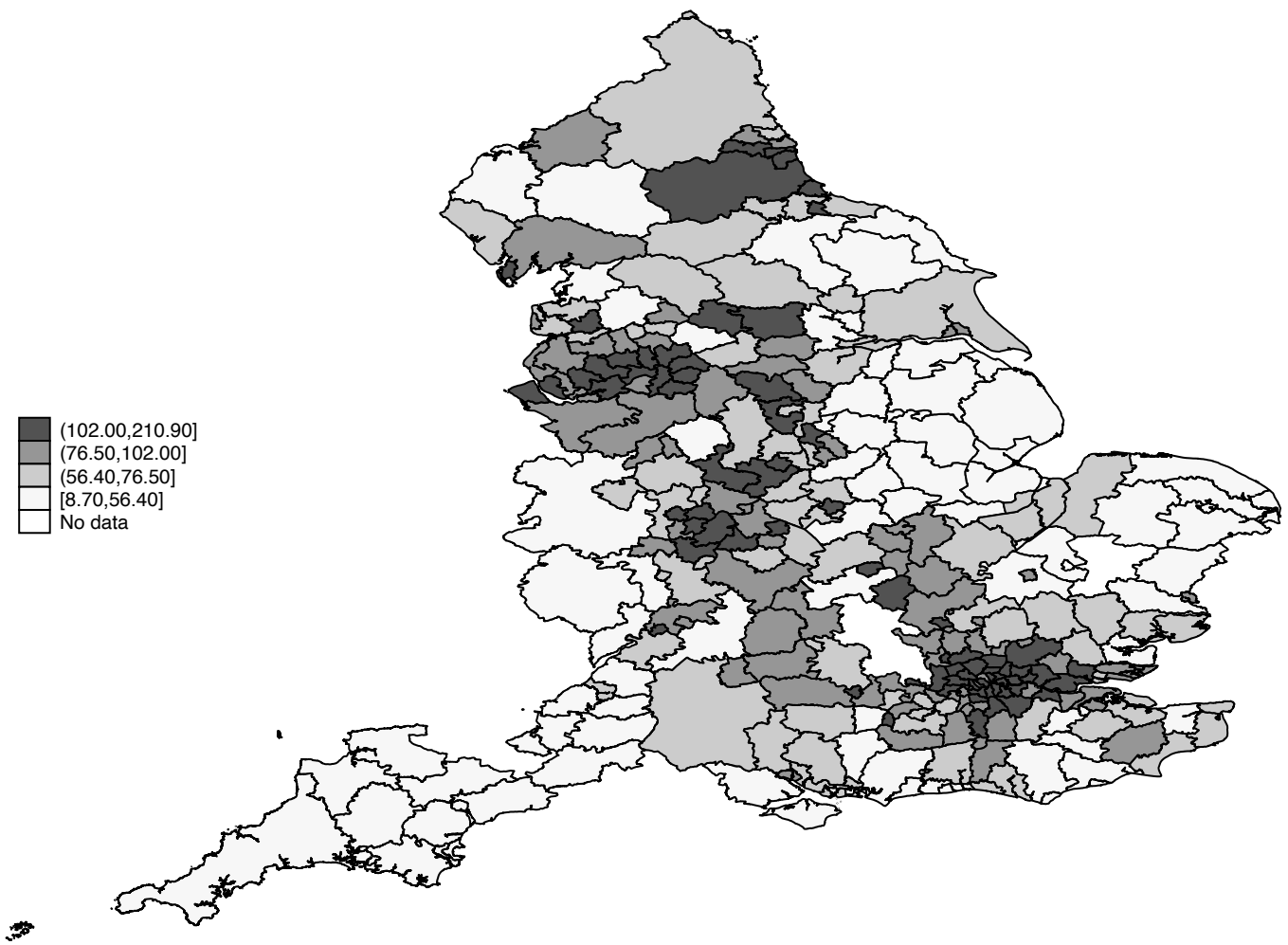

Notes: Shades on the map correspond to values of the age-standardised COVID-19 mortality rate.

\subsection{Analysis using untransformed variables}

Since some of the variables were skewed, two separate analyses were undertaken: one using untransformed variables, and one using logged variables. This sub-section reports the former. A correlation matrix is given in Table 1. The correlations of the predictor variables with COVID-19 mortality rate are shown in the first column. \% black or Asian has the strongest association, followed by cumulative confirmed cases rate and \% in multi-generational households. The deprivation index has a weak positive association with COVID-19 mortality rate, while the health index has a weak negative association with COVID-19 mortality rate. The latter result is most likely attributable to the crudeness of the health index, as well as the fact that COVID-19 mortality rate is standardised for age, meaning that it already captures most or all of the variance associated with long-term health conditions. Average household size and population density have moderate-to-strong, positive associations with COVID-19 mortality rate.

Some other results of interest are as follows. \% black or Asian has a very strong association with $\%$ multi-generational households, and has a strong association with average household size. The health index and the deprivation index are strongly associated with one another. Scatterplots of the relationships between predictor variables and COVID-19 mortality rate are given in Figure 2 . 
Table 1. Correlation matrix for the main variables used in the study.

\begin{tabular}{|l|c|c|c|c|c|c|c|c|}
\hline & $\begin{array}{c}\text { COVID-19 } \\
\text { mortality } \\
\text { rate }\end{array}$ & $\begin{array}{c}\text { Cumulative } \\
\text { confirmed } \\
\text { cases rate }\end{array}$ & $\begin{array}{c}\text { Population } \\
\text { density }\end{array}$ & $\begin{array}{c}\text { \% black or } \\
\text { Asian }\end{array}$ & $\begin{array}{c}\text { Average } \\
\text { household } \\
\text { size }\end{array}$ & $\begin{array}{c}\text { \% multi- } \\
\text { generational } \\
\text { households }\end{array}$ & $\begin{array}{c}\text { Deprivation } \\
\text { index }\end{array}$ & Health index \\
\hline $\begin{array}{l}\text { COVID-19 } \\
\text { mortality } \\
\text { rate }\end{array}$ & 1.00 & 1.00 & & & & & & \\
\hline $\begin{array}{l}\text { Cumulative } \\
\text { confirmed } \\
\text { cases rate }\end{array}$ & 0.67 & 0.36 & 1.00 & & & & & \\
\hline $\begin{array}{l}\text { Population } \\
\text { density }\end{array}$ & 0.61 & 0.36 & 0.69 & 1.00 & & & & \\
\hline $\begin{array}{l}\% \text { black or } \\
\text { Asian }\end{array}$ & 0.70 & 0.20 & 0.14 & 0.62 & 1.00 & & & \\
\hline $\begin{array}{l}\text { Average } \\
\text { household } \\
\text { size }\end{array}$ & 0.48 & 0.36 & 0.58 & 0.92 & 0.73 & 1.00 & & \\
\hline $\begin{array}{l}\% \text { multi- } \\
\text { generational } \\
\text { households }\end{array}$ & 0.66 & 0.08 & 0.00 & 0.13 & 0.05 & 0.23 & 1.00 & \\
\hline $\begin{array}{l}\text { Deprivation } \\
\text { index }\end{array}$ & 0.18 & 0.03 & -0.12 & -0.18 & -0.34 & -0.10 & 0.80 & 1.00 \\
\hline $\begin{array}{l}\text { Poor health } \\
\text { index }\end{array}$ & -0.07 & 0.10 & & & \\
\hline
\end{tabular}

Notes: The COVID-19 mortality rate is age-standardised.

Figure 2. Scatterplots of the relationships between predictor variables and COVID-19 mortality rate.
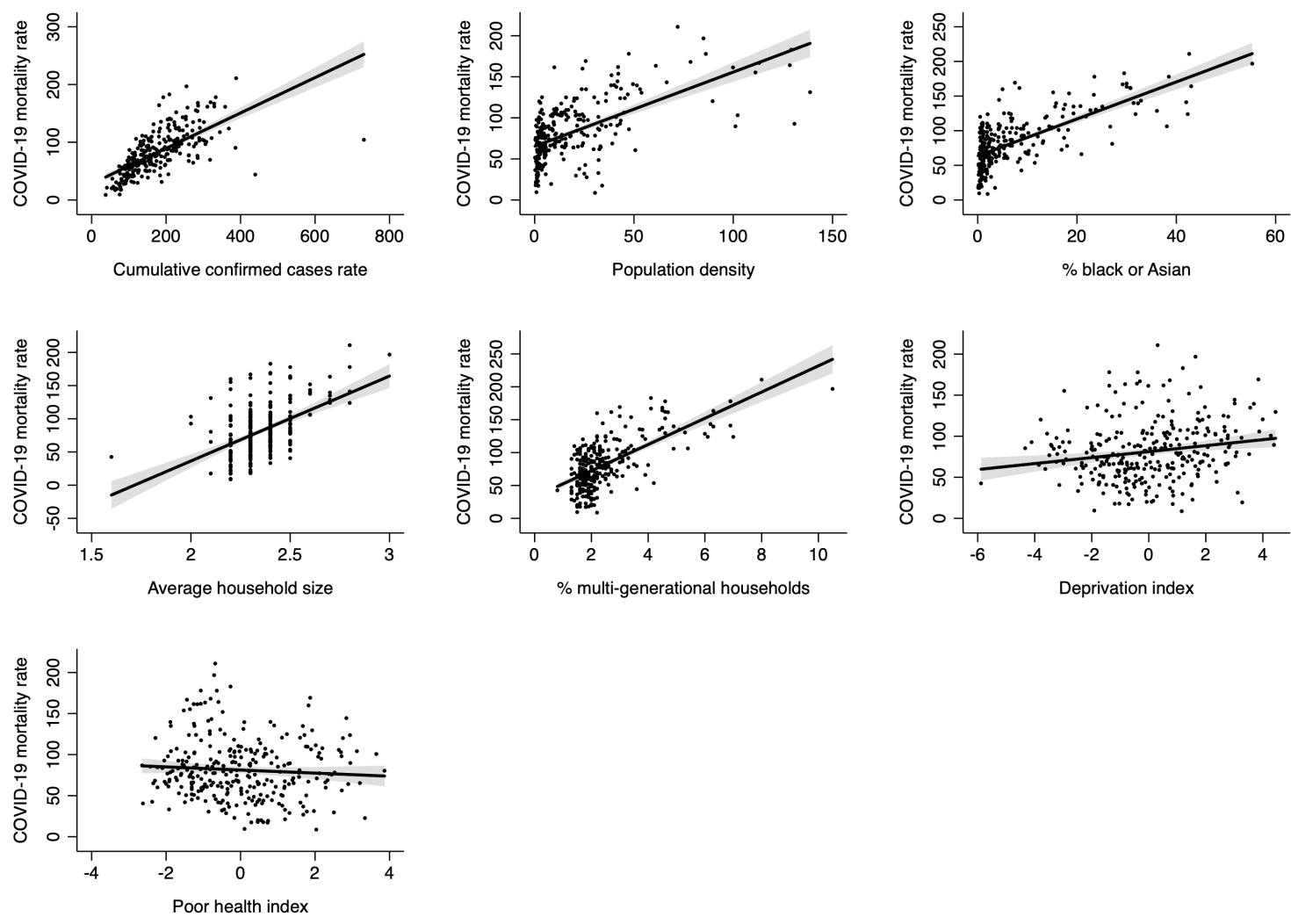

Notes: The y-axis variable is the age-standardised COVID-19 mortality rate.

Estimates from multiple linear regression models of COVID-19 mortality rate are given in Table 2. Column (1) shows estimates from the preferred model. Five predictor variables explain $73 \%$ of the variance in 
COVID-19 mortality across local authorities: cumulative confirmed cases rate; population density; \% black or Asian; average household size; and deprivation index. All five associations make theoretical sense. COVID-19 mortality is higher where there are more cases of COVID-19, where there are more people per square kilometre (leading to higher transmission), where there are more black and Asian people (who are believed to have an elevated risk of death from COVID-19), where the average household size is greater (leading to higher transmission), and where the level of deprivation is greater (leading to higher transmission and/or risk of death).

Table 2. Multiple linear regression models of COVID-19 mortality rate.

\begin{tabular}{|c|c|c|c|c|c|}
\hline & $\begin{array}{c}1) \\
\text { COVID-19 } \\
\text { mortality rate }\end{array}$ & $\begin{array}{c}(2) \\
\text { COVID-19 } \\
\text { mortality rate }\end{array}$ & $\begin{array}{c}\text { (3) } \\
\text { COVID-19 } \\
\text { mortality rate }\end{array}$ & $\begin{array}{c}(4) \\
\text { COVID-19 } \\
\text { mortality rate }\end{array}$ & $\begin{array}{c}(5) \\
\text { COVID-19 } \\
\text { mortality rate }\end{array}$ \\
\hline $\begin{array}{l}\text { Cumulative conf. } \\
\text { cases rate }\end{array}$ & $0.203^{*+* x}$ & $0.211^{* * *}$ & $0.208^{* * *}$ & $0.202^{* * *}$ & $0.207^{*+* x}$ \\
\hline Population density & $0.446^{* * *}$ & $0.484^{* * t}$ & $0.240^{* * *}$ & $0.427^{* * *}$ & $0.437^{* * *}$ \\
\hline$\%$ black or Asian & $0.642^{* *}$ & $1.539^{* * *}$ & $1.678^{* * *}$ & $0.753^{* *}$ & $0.606^{*}$ \\
\hline $\begin{array}{l}\text { Average } \\
\text { household size }\end{array}$ & $64.369^{* * *}$ & $84.523^{* * *}$ & & $68.164^{* * *}$ & $52.003^{* * *}$ \\
\hline Deprivation index & $2.295^{* * *}$ & $4.757^{*+*}$ & $1.931^{* *}$ & & $4.495^{* * t}$ \\
\hline $\begin{array}{l}\% \text { multi-gen. } \\
\text { households }\end{array}$ & & $-11.118^{* * *}$ & -0.904 & & \\
\hline Poor health index & & -2.519 & & $1.935^{*}$ & $-3.612^{*}$ \\
\hline Constant & $-117.343^{* * *}$ & $-145.510^{* \star *}$ & $32.106^{* * *}$ & $-126.534^{* * *}$ & $-88.657^{* *}$ \\
\hline Observations & 292 & 292 & 292 & 292 & 292 \\
\hline$R^{2}$ & 0.73 & 0.75 & 0.71 & 0.72 & 0.74 \\
\hline
\end{tabular}

Notes: Entries are unstandardized regression coefficients. The dependent variable is the age-standardised COVID-19 mortality rate. Significance levels: ${ }^{*} p<0.05,{ }^{* *} p<0.01,{ }^{* * *} p<0.001$.

It is somewhat surprising that population density and average household size reach significance when cumulative confirmed cases rate is already in the model, given that one might have assumed cumulative confirmed cases rate would capture all the variance associated with prevalence of COVID-19. However, it is possible that this is only a rough measure of prevalence (due to asymptomatic cases, underreporting, false test results etc.), and that population density and average household size are therefore capturing unmeasured transmission of the virus. Another possibility is that these variables are capturing unmeasured aspects of socio-economic disadvantage, or factors such as air pollution (Ogen, 2020; Bianconi et al., 2020; Travaglio et al., 2020). The finding that \% black or Asian reaches significance is consistent with evidence from other studies (ONS, 2020c; OpenSAFELY Collaborative, 2020; Cook et al., 2020; Li et al., 2020; PHE, 2020). The association may be explained by some combination of: unmeasured socio-economic disadvantage; behavioural differences; greater prevalence of pre-existing conditions; and vitamin D deficiency. In fact, the latter hypothesis seems particular promising (Ridley, 2020; Carl, 2020; Lanham-New et al., 2020; Haroon et al., 2020; Brown, 2020).

Column (2) shows estimates from a model containing all the predictor variables. \% multigenerational households has a negative coefficient, while the health index does not reach statistical significance. Column (3) shows estimates from a model that excludes average household size but includes 
$\%$ multi-generational households. The latter variable does not reach statistical significance, whereas \% black or Asian remains highly significant. Column (4) shows estimates from a model that includes the health index but not the deprivation index. And column (5) shows estimates from a model that includes both the health index and the deprivation index. The former variable has a negative coefficient, whereas the latter has a highly significant positive coefficient.

\subsection{Analysis using logged variables}

This section reports the analysis using logged variables. A correlation matrix is given in Table 3. The correlations of the predictor variables with log COVID-19 mortality rate are shown in the first column. Log cumulative confirmed cases rate has the strongest association, followed by log \% black or Asian. The deprivation index has a weak positive association with log COVID-19 mortality rate, while the health index has a weak negative association with log COVID-19 mortality rate. Average household size, log \% multigenerational households and log population density have moderate-to-strong, positive associations with log COVID-19 mortality rate. Scatterplots of the relationships between predictor variables and log COVID19 mortality rate are given in Figure 3.

Table 3. Correlation matrix for the main variables used in the study (logged).

\begin{tabular}{|l|c|c|c|c|c|c|c|c|}
\hline & $\begin{array}{c}\text { Log COVID- } \\
19 \text { mortality } \\
\text { rate }\end{array}$ & $\begin{array}{c}\text { Log cum. } \\
\text { conf. cases } \\
\text { rate }\end{array}$ & $\begin{array}{c}\text { Log } \\
\text { population } \\
\text { density }\end{array}$ & $\begin{array}{c}\text { Log \% black } \\
\text { or Asian }\end{array}$ & $\begin{array}{c}\text { Average } \\
\text { household } \\
\text { size }\end{array}$ & $\begin{array}{c}\text { Log \% multi- } \\
\text { generational } \\
\text { households }\end{array}$ & $\begin{array}{c}\text { Deprivation } \\
\text { index }\end{array}$ & Health index \\
\hline $\begin{array}{l}\text { Log COVID- } \\
19 \text { mortality } \\
\text { rate }\end{array}$ & 1.00 & 1.00 & & & & & & \\
\hline $\begin{array}{l}\text { Log cum. } \\
\text { conf. cases } \\
\text { rate }\end{array}$ & 0.77 & 0.47 & 1.00 & & & & & \\
\hline $\begin{array}{l}\text { Log } \\
\text { population } \\
\text { density }\end{array}$ & 0.57 & 0.46 & 0.75 & 1.00 & & & & \\
\hline $\begin{array}{l}\text { Log\% black } \\
\text { or Asian }\end{array}$ & 0.65 & 0.25 & 0.25 & 0.53 & 1.00 & & & \\
\hline $\begin{array}{l}\text { Average } \\
\text { household } \\
\text { size }\end{array}$ & 0.44 & 0.41 & 0.64 & 0.79 & 0.70 & 1.00 & & \\
\hline $\begin{array}{l}\text { Log\% multi- } \\
\text { generational } \\
\text { households }\end{array}$ & 0.55 & 0.06 & 0.19 & 0.06 & 0.05 & 0.28 & 1.00 & \\
\hline $\begin{array}{l}\text { Deprivation } \\
\text { index }\end{array}$ & 0.15 & -0.03 & -0.01 & -0.29 & -0.34 & -0.07 & 0.80 & 1.00 \\
\hline $\begin{array}{l}\text { Poor health } \\
\text { index }\end{array}$ & -0.10 & 0.06 & & & \\
\hline
\end{tabular}

Notes: The COVID-19 mortality rate is age-standardised. 
Figure 3. Scatterplots of the relationships between predictor variables and COVID-19 mortality rate (logged).
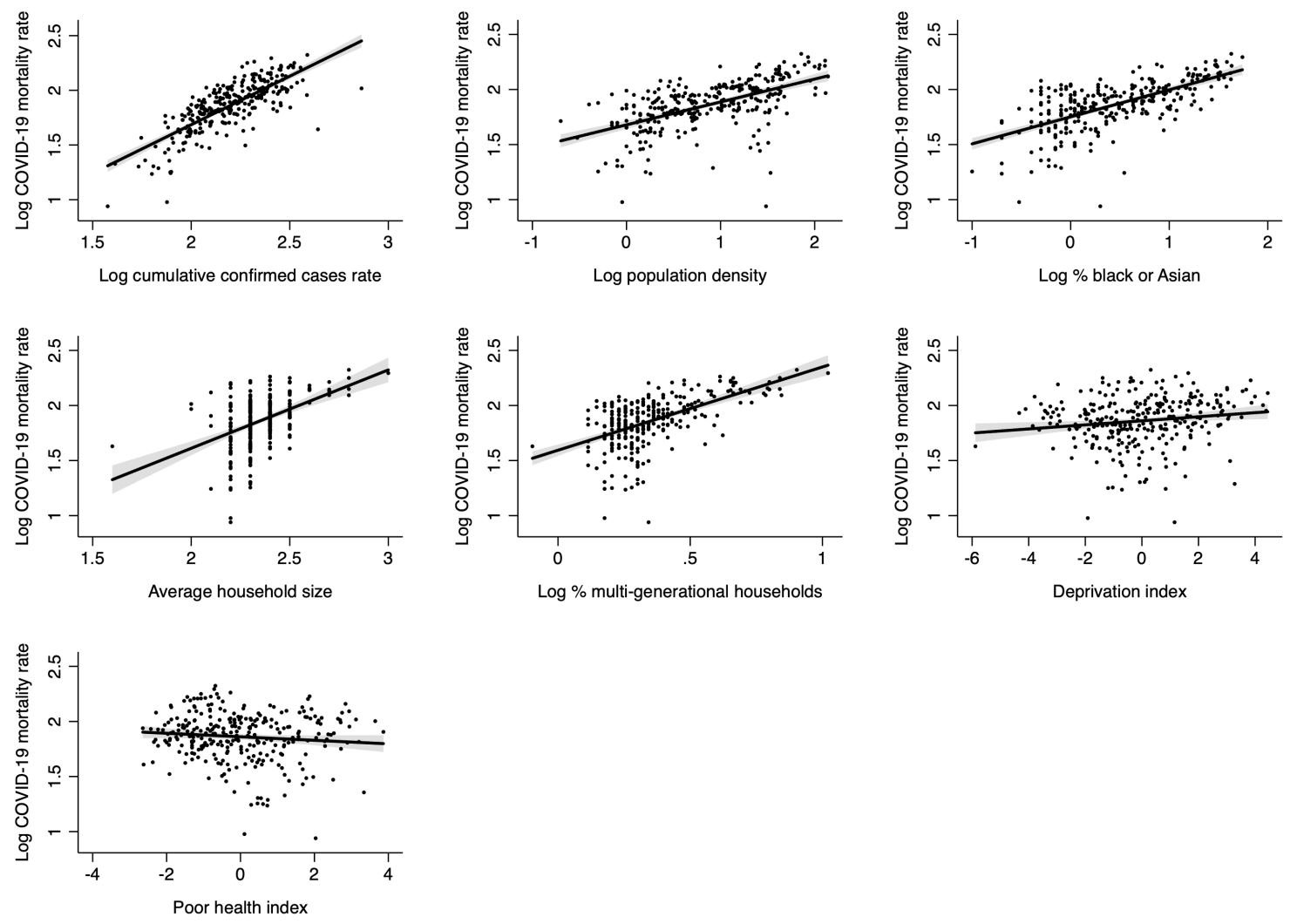

Notes: The y-axis variable is the log of age-standardised COVID-19 mortality rate.

Estimates from multiple linear regression models of log COVID-19 mortality rate are given in Table 4 . Column (1) shows estimates from the preferred model. Four predictor variables explain $72 \%$ of the variance in COVID-19 mortality across local authorities: log cumulative confirmed cases rate; log \% black or Asian; average household size; and deprivation index. Column (2) shows estimates from a model containing all the predictor variables. \% multi-generational households has a negative coefficient, while neither log population density nor the health index reaches statistical significance. It is noteworthy that log population density does not reach statistical significance in the model of log COVID-19 mortality rate, given that population density was highly significant in all the models of COVID-19 mortality rate (see Table 2). This difference is probably attributable to the fact that confirmed cases rate is much more strongly associated with COVI-19 mortality rate when using logged variables than when using untransformed variables (compared Table 1 and Table 3). 
Table 4. Multiple linear regression models of log COVID-19 mortality rate.

\begin{tabular}{|c|c|c|c|c|c|}
\hline & $\begin{array}{c}\text { (1) } \\
\text { Log COVID-19 } \\
\text { mortality rate }\end{array}$ & $\begin{array}{c}\text { (2) } \\
\text { Log COVID-19 } \\
\text { mortality rate }\end{array}$ & $\begin{array}{c}\text { (3) } \\
\text { Log COVID-19 } \\
\text { mortality rate }\end{array}$ & $\begin{array}{c}\text { (4) } \\
\text { Log COVID-19 } \\
\text { mortality rate }\end{array}$ & $\begin{array}{c}\text { (5) } \\
\text { Log COVID-19 } \\
\text { mortality rate }\end{array}$ \\
\hline $\begin{array}{l}\text { Log cumulative } \\
\text { conf. cases rate }\end{array}$ & $0.684^{* * * t}$ & $0.690^{*+* t}$ & $0.686^{* * *}$ & $0.679^{* * *}$ & $0.697^{* * *}$ \\
\hline $\begin{array}{l}\text { Log \% black or } \\
\text { Asian }\end{array}$ & $0.114^{* * *}$ & $0.128^{* * *}$ & $0.148^{* * *}$ & $0.121^{* * *}$ & $0.104^{* * *}$ \\
\hline $\begin{array}{l}\text { Average } \\
\text { household size }\end{array}$ & $0.211^{* * * t}$ & $0.347^{* * *}$ & & $0.239^{* * *}$ & $0.159^{*}$ \\
\hline Deprivation index & $0.011^{* *}$ & $0.024^{* *}$ & $0.012^{* *}$ & & $0.022^{* *}$ \\
\hline $\begin{array}{l}\text { Log population } \\
\text { density }\end{array}$ & & 0.033 & & & \\
\hline $\begin{array}{l}\text { Log } \% \text { multi-gen. } \\
\text { households }\end{array}$ & & $-0.314^{* *}$ & -0.038 & & \\
\hline Poor health index & & -0.014 & & 0.010 & -0.019 \\
\hline Constant & -0.188 & $-0.446^{*}$ & $0.300^{* * * *}$ & -0.247 & -0.091 \\
\hline Observations & 292 & 292 & 292 & 292 & 292 \\
\hline$R^{2}$ & 0.72 & 0.73 & 0.71 & 0.72 & 0.72 \\
\hline
\end{tabular}

Notes: Entries are unstandardized regression coefficients. The dependent variable is the log of age-standardised COVID-19 mortality rate. Significance levels: ${ }^{*} p<0.05,{ }^{* *} p<0.01,{ }^{* * *} p<0.001$.

Column (3) shows estimates from a model that excludes average household size but includes log \% multigenerational households. The latter variable does not reach statistical significance, whereas log \% black or Asian remains highly significant. Column (4) shows estimates from a model that includes the health index but not the deprivation index. The former variable does not reach statistical significance. And column (5) shows estimates from a model that includes both the health index and the deprivation index. The health index does not reach statistical significance, whereas the deprivation index has a highly significant positive coefficient.

\section{Conclusion}

This study analysed COVID-19 mortality at the local authority level in England. Two separate analyses were undertaken: one using untransformed variables, and one using logged variables. In the former, five variables explained $73 \%$ of the variance in COVID-19 mortality rate: cumulative confirmed cases rate, population density, \% black or Asian, average household size, and a deprivation index. In the latter, four variables explained $72 \%$ of the variance in log COVID-19 mortality rate: log cumulative confirmed cases rate, $\log \%$ black or Asian, average household size, and the deprivation index. Cumulative confirmed cases rate, average household size and \% black or Asian were the strongest and most consistent predictors of COVID-19 mortality. None of the associations in this study should be considered causal, given that they were derived from ecological analyses of observational data. (Code is provided on the OSF page. All data are publicly available.) 


\section{References}

Bianconi, V., Bronzo, P., Banach, M., Sahebkar, A., Mannarino, M.R. \& Pirro, M. (2020). Particulate matter pollution and the COVID-19 outbreak: results from Italian regions and provinces. Archives of Medical Science, published online.

Brown, R. (2020). Is ethnicity linked to incidence or outcomes of covid-19? [Rapid Response]. The BMJ, 369 , published online.

Carl, N. (2020). Why Are Non-White Britons More Likely to Die of COVID-19? Medium, published online.

Cook, T., Kursumovic, E. \& Lennane, S. (2020). Exclusive: deaths of NHS staff from covid-19 analysed. HSJ, published online.

Haroon, S., Cooper, J., Anand, A., Nirantharakumar, K. \& Hewison, M. (2020). Is ethnicity linked to incidence or outcomes of covid-19? [Rapid Response]. The BMJ, 369, published online.

Lanham-New, S.A., Webb, A.R., Cashman, K.D. et al. (2020). Vitamin D and SARS-CoV-2 virus/COVID-19 disease. BMJ Nutrition, Prevention \& Health, 0, published online.

Li, A.Y., Hannah, T.H., Durbin, J. et al. (2020). Multivariate Analysis of Factors Affecting COVID-19 Case and Death Rate in U.S. Counties: The Significant Effects of Black Race and Temperature. medRxiv, published online.

Ogen, Y. (2020). Assessing nitrogen dioxide (NO2) levels as a contributing factor to coronavirus (COVID19) fatality. Science of The Total Environment, 726.

ONS. (2012). 2011 Census: Key Statistics for Local Authorities in England and Wales. Office for National Statistics, published online.

ONS. (2018). Regional gross disposable household income by local authority. Office for National Statistics, published online.

ONS. (2020a). Deaths involving COVID-19 by local area and socioeconomic deprivation: deaths occurring between 1 March and 17 April 2020. Office for National Statistics, published online.

ONS. (2020b). Deaths involving COVID-19 by local area and socioeconomic deprivation: deaths occurring between 1 March and 31 May 2020. Office for National Statistics, published online.

ONS. (2020c). Coronavirus (COVID-19) related deaths by ethnic group, England and Wales: 2 March 2020 to 10 April 2020. Office for National Statistics, published online.

OpenSAFELY Collaborative, Williamson, E., Walker, A.J. et al. (2020). OpenSAFELY: factors associated with COVID-19-related hospital death in the linked electronic health records of 17 million adult NHS patients. medRxiv, published online.

PHE. (2020). Disparities in the risk and outcomes of COVID-19. Public Health England, published online.

Ridley, M. (2020). It is time to take seriously the link between Vitamin D deficiency and more serious Covid-19 symptoms. The Telegraph, published online.

Rose, T.C., Mason, K., Pennington, A. et al. (2020). Inequalities in COVID19 mortality related to ethnicity and socioeconomic deprivation. medRxiv, published online.

Travaglio, M., Yu, Y., Popovic, R. et al. (2020). Links between air pollution and COVID-19 in England. medRxiv, published online.

UK Government. (2020). Coronavirus (COVID-19) in the UK: Data dashboard. GOV.UK, published online. 